Landsberg/Pinkau · Holzsysteme für den Hochbau 
Heike Landsberg

Stephan Pinkau

\section{Holzsysteme \\ für den \\ Hochbau}

Grundlagen

Systeme

Beispiele

Verlag W. Kohlhammer 
Die Deutsche Bibliothek - CIP-Einheitsaufnahme

\section{Landsberg, Heike:}

Holzsysteme für den Hochbau : Grundlagen, Systeme, Beispiele /

Heike Landsberg ; Stephan Pinkau. -

Stuttgart ; Berlin ; Köln : Kohlhammer, 1999

ISBN 978-3-8348-1662-7 ISBN 978-3-322-99952-8 (eBook)

DOI 10.1007/978-3-322-99952-8

Die technischen Angaben erfolgen nach bestem Wissen.

Eine Haftung kann nicht übernommen werden.

Alle Rechte vorbehalten

(C) 1999 W. Kohlhammer GmbH

Stuttgart Berlin Köln

Verlagsort: Stuttgart

Umschlag: Data Images $\mathrm{GmbH}$

Gesamtherstellung:

W. Kohlhammer Druckerei GmbH + Co. Stuttgart 


\section{Inhalt}

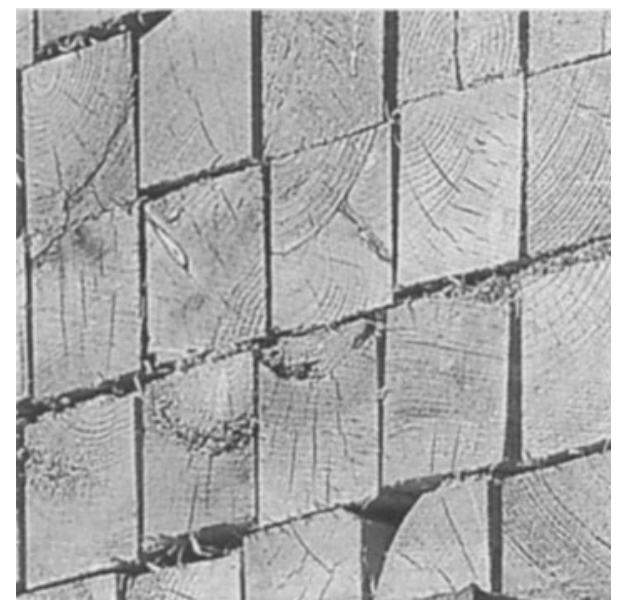

1. Grundlagen zum Systembau mit Holz

$1.1 \quad$ Der Stand der Dinge . . . . . . . . . . . . . . . . 10

1.2 Die bisherige Entwicklung . . . . . . . . . . . 12

$1.3 \quad$ Wege der Rationalisierung am Bau $\ldots \ldots \ldots \ldots \ldots$

1.4 Bauen mit Systemen . . . . . . . . . . . . . . . . 20

1.5 Werkstoff Holz . . . . . . . . . . . . . . . . . 26

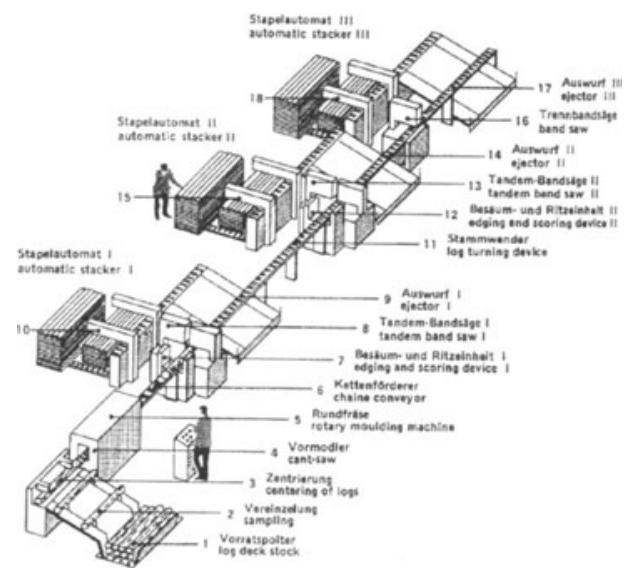

\section{Holzsysteme}

Bauholz ........................... 35

Brettschichtholz .................. 41

Holzverbundwerkstoffe ... . . . . . . . . . . . . 49

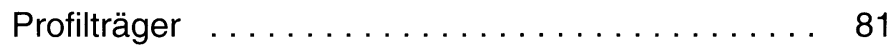

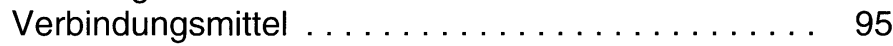

Systeme aus Stäben . . . . . . . . . . . . . . . . . 109

Holzrahmenbauwände . . . . . . . . . . . . . 115

Massivholzwände . . . . . . . . . . . . . . . . 123

Hohlkastenwände und -decken . . . . . . . . . . . . 131

Holzrahmenbau- und Rippendecken . . . . . . . . . . 139

Massivholzdecken ................. 149

Raumzellen ..................... 157

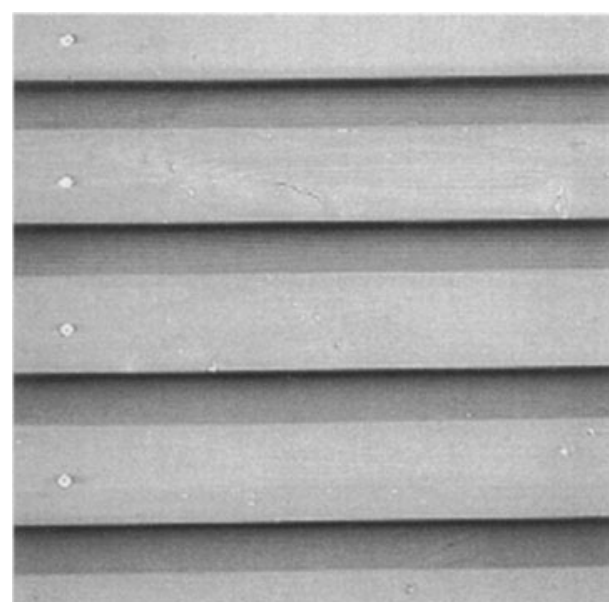

3. Beispiele zur Verwendung von Holzsystemen

3.1 Wohnbauten ................... 163

3.2 Öffentliche Bauten und Gewerbebauten . . . . . . . . 185 


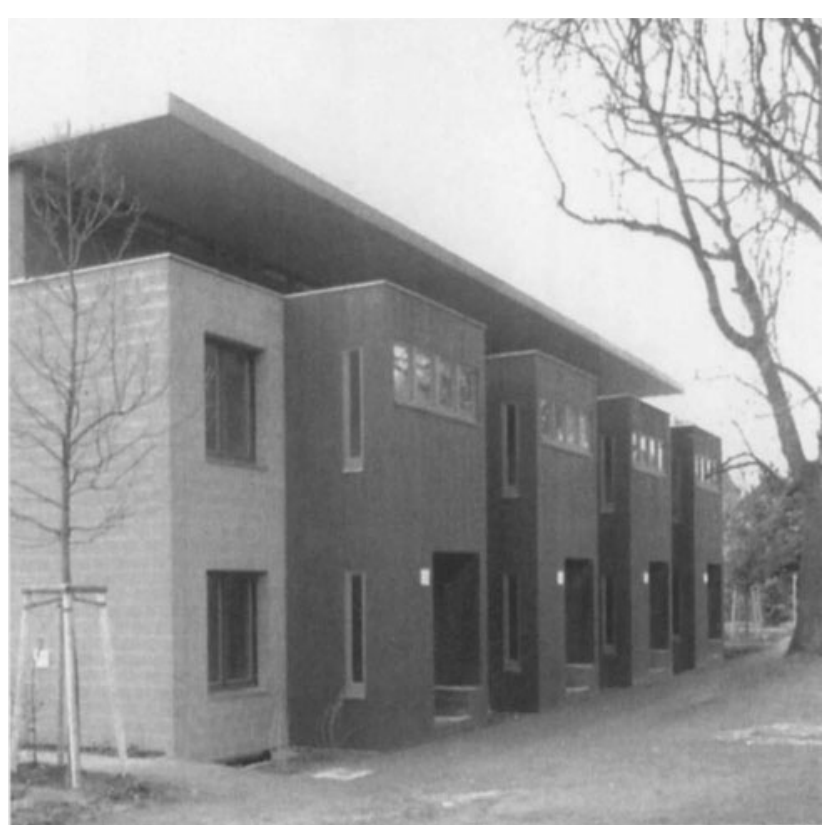

\section{Vorwort}

Holz bietet sich seit jeher als leicht verfügbarer und preiswerter Baustoff an.

Durch die Art seiner Entstehung liegt es bereits im Urzustand stabförmig vor und braucht vor seiner Verwendung nur auf Format geschnitten zu werden.

Die modernen Entwicklungen im Holzbau setzen allerdings nicht an dieser Stelle an. Vielmehr verlangt der zunehmende Vorfertigungsgrad eine Entwicklung von Holzsystemen, die sich mit geringem Montageaufwand vor Ort zusammensetzen lassen.

Entwurfliche und konstruktive Überlegungen hierzu gehen zurück auf Architekten wie F.L. Wright, K. Wachsmann, W. Gropius und H. Poelzig.

Bei industriell vorgefertigten Holzsystemen kann das geschnittene Ausgangsmaterial nur in manchen Fällen direkt eingesetzt werden, meistens sind bestimmte Holzeigenschaften in einer automatisierten Fertigung hinderlich.

Dann werden die Stämme erst zu Brettern, Furnieren oder Spänen verarbeitet, daraus stab- oder plattenförmige Halbzeuge erstellt und anschließend komplexe Systeme gefertigt.
Dieses Buch stellt heute verfügbare Holzsysteme erstmals in der Übersicht dar.

Grundlage der Darstellung sind Vorlesungen von Stephan Pinkau als Gastprofessor an der Technischen Universität Berlin im Fach Baukonstruktion, eine Analyse verfügbarer Holzsysteme und realisierter Projekte in Holzbauweise.

Herrn Dipl. Ing. Gerke, Herrn Dipl. Ing. Voß und Herrn cand. arch. Bonzel danken wir für die gute Zusammenarbeit.

Ergänzende Informationen finden Sie im Internet unter http://www.snafu.de/ landsberg.pinkau oder unter http://www.fh-anhalt.de

Heike Landsberg

Stephan Pinkau 


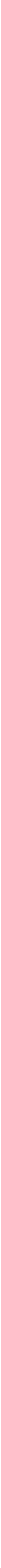

